\title{
Semantic activation in the absence of perceptual awareness
}

\author{
JUAN J. ORTELLS and MARÍA TERESA DAZA \\ University of Almeria, Almeria, Spain \\ and \\ ELAINE FOX \\ University of Essex, Colchester, England
}

\begin{abstract}
Participants performed a semantic categorizationtask on a target that was preceded by a prime word belonging either to the same category ( $20 \%$ of trials) or to a different category ( $80 \%$ of trials). The prime was presented for $33 \mathrm{msec}$ and followed either immediately or after a delay by a pattern mask. With the immediate mask, reaction times (RTs) were shorter on related than on unrelated trials. This facilitatory priming reached significance at prime-target stimulus onset asynchronies (SOAs) of $400 \mathrm{msec}$ or less and remained unaffected by task practice. With the delayed mask, RTs were longer on related than on unrelated trials. This reversed (strategic) semantic priming proved to be significant (1) only at a prime-target SOA of $400 \mathrm{msec}$ or longer and (2) after the participants had some practice with the task. The present findings provide further evidence that perceiving a stimulus with and without phenomenological awareness can lead to qualitatively different behavioral consequences.
\end{abstract}

Can stimulus information be perceived without awareness? This question has been the focus of research and controversy for more than 100 years (for recent reviews, see Merikle \& Daneman, 1998, and Merikle, Smilek, \& Eastwood, 2001). Despite its relatively long history, research on perception without awareness has been plagued by continual controversy. Much of this controversy stems directly from the logic underlying the dissociation paradigm, which has been the predominant tool used in experimental studies.

The basic assumption underlying the dissociation paradigm is that unconscious perception can be demonstrated by means of the dissociation between two measures of perception: one that is assumed to assess perception with awareness and the other, perception without awareness. A direct measure of perception reflects the effect of a perceived stimulus on the instructed responses to that stimulus, and thus indicates whether relevant stimulus information has been consciously perceived. In contrast, an indirect measure of perception reflects an uninstructed effect of the stimulus on behavior and is an indication of

This research was supported partly by Grant BSO2000-1411-C02-02 from the Ministerio de Ciencia y Tecnología, Dirección General de Investigación (Spain), to the first author. The findings of Experiment 2 were presented at the III Congress of the Spanish Society of Experimental Psychology (SEPEX), March, 2000, in Barcelona. We thank Eyal Reingold, Zhe Chen, and one anonymous reviewer for helpful and valuable comments on an earlier version of the manuscript. Correspondence should be sent to J. J. Ortells, Departamento de Neurociencia y Ciencias de la Salud, Facultad de Humanidades y Ciencias de la Educación, Universidad de Almería, Almería 04120, Spain (e-mail: jortells@ual.es). unconsciously perceived information. Perception without awareness is demonstrated when the indirect test is sensitive to stimulus information to which the direct test shows null sensitivity.

In spite of this relatively straightforward logic underlying the dissociation paradigm, it has proven difficult to design experiments that provide compelling, uncontroversial evidence of perception without awareness. The main problem has been a lack of agreement about what constitutes an adequate direct measure of conscious perception (see, e.g., Eriksen, 1960; Holender, 1986; Reingold \& Merikle, 1990). Whereas for some researchers subjective measures based on observers' introspective selfreports would constitute a satisfactory index of stimulus awareness, for others the absence of relevant conscious experiences is much better indexed by some objective (behavioral) measure that demonstrates an observer's inability to discriminate between alternative stimulus states.

The interpretation of a dissociation pattern depends on the assumptions being made about the relation of conscious and unconscious perception to performance on direct and indirect tasks. In the context of the classic dissociation paradigm, it has been suggested that in order to provide compelling evidence for unconscious perception, the direct measure must be assumed to be sensitive to all relevant conscious effects of stimuli (i.e., an exhaustiveness assumption), and such a measure must exhibit null sensitivity. If it is not, any dissociation between measures may indicate simply that the direct and indirect indices are sensitive to different aspects of consciously perceived stimuli. In addition, the direct measure should be influ- 
enced exclusively by conscious processes. If a direct effect is sensitive to both consciously and unconsciously perceived information, then any attempt to establish null sensitivity for the direct measure could eliminate or underestimate evidence for unconscious perception. Note, however, that requiring direct measures that reflect, both exclusively and exhaustively, all relevant consciously perceived information may be too stringent a requirement for the demonstration of unconscious influences. As was pointed out by Reingold and Merikle (1988, 1990; see also Merikle \& Reingold, 1998; Reingold, in press), it is unrealistic to expect that any particular direct measure of perception could actually be sensitive to all relevant conscious experiences. These authors also considered it implausible that unconscious influences should not contribute to performance on direct measures. It seems more likely that any direct effect (like any indirect one) might stem from both conscious and unconscious contributions (see also Jacoby, Lindsay, \& Toth, 1992).

A further weakness of the dissociation paradigm is that any attempt to find an indirect effect in the absence of a direct effect would require the acceptance of a null hypothesis (i.e., the hypothesis of no direct effect), and this is statistically problematic. As Merikle and Joordens (1997a) noted, it is impossible to demonstrate that null sensitivity necessarily indicates that no relevant information was consciously perceived. There is always the possibility that some amount of stimulus information was detected on at least some occasions that eluded detection by conventional direct tasks.

Finally, it is important to note that traditional studies of perception without awareness have often used a facilitation paradigm, whereby the same pattern of results was produced by effects on unconscious perception as by those on conscious perception. According to Debner and Jacoby (1994), because both types of processes can contribute to performance in a similar manner (i.e., by facilitating it), it is difficult to determine whether the supposedly unconscious influences might be partially or completely attributed to any residual conscious perception.

Because of these limitations related to the dissociation paradigm, a series of alternative approaches to studying perception without awareness has been developed. These require neither the use of exhaustive measures of awareness nor a convincing demonstration of a null direct effect (see, e.g., Debner \& Jacoby, 1994; Draine \& Greenwald, 1998; Greenwald, Draine, \& Abrams, 1996; Merikle \& Joordens, 1997a, 1997b; Reingold \& Merikle, 1988). These authors argue that, rather than simply asking whether a stimulus can be unconsciously perceived, a much more interesting question concerns how unconscious perception differs (if at all) from conscious perception. The experimental logic is to contrast perception with and without awareness in order to determine whether a stimulus can have qualitatively different consequences on cognitive and affective reactions, depending on whether the item was perceived consciously or unconsciously. The qualitative differences approach assumes that consciously perceived information enables the individual to act intentionally on the world and to produce effects on it, whereas information perceived without awareness leads to more automatic reactions that cannot be controlled by the individual (Merikle et al., 2001).

A good example of behavioral measures that are influenced in opposite ways by consciously and unconsciously perceived information comes from an elegant series of Stroop priming studies by Merikle and colleagues. They showed that individuals could use predictive strategies based on stimulus redundancy only when the predictive stimuli are consciously perceived (e.g., Cheesman \& Merikle, 1986; Merikle \& Joordens, 1997a, 1997b; Merikle, Joordens, \& Stolz, 1995). Their experiments were based on a variant of the Stroop (1935) color-word interference task, in which two color words (e.g., RED and GREEN) are used to prime responses to a probe target consisting of a color patch (or a series of ampersands) that was red or green. The standard result found with this task is that responses to the probe target (e.g., a red patch or a series of red ampersands) are longer when the target follows an incongruent color word (i.e., GREEN) than when it follows a congruent color word (i.e., RED). This interference effect presumably occurs because participants cannot avoid reading the word even if they are not required to read it, and reading a word that refers to a conflicting color concept interferes with responding correctly to the color target. However, the typical Stroop interference is reversed [i.e., reaction times (RTs) are shorter on incongruent than on congruent trials] whenever incongruent prime-target pairings (e.g., GREEN-red target) occur more frequently than congruent prime-target pairings (e.g., RED-red target). A plausible explanation of the reversed Stroop priming effect is that participants capitalize on the predictive information provided by the prime words (see, e.g., Merikle et al., 1995). Given that there are only two possible colors, participants learn to expect that the target color on each trial will be the color not named by the preceding prime word, thus facilitating performance on the incongruent trials (and slowing performance on the congruent ones). Interestingly, Merikle and colleagues observed that participants adopt this kind of predictive strategy only when the prime words are consciously perceived. Otherwise, the standard interference effect is found. For example, Merikle and Joordens (1997b, Experiment $1 \mathrm{~A}$ ) presented a single central prime word (RED or GREEN in the color gray) for $33 \mathrm{msec}$, followed either immediately or after a delay of $134 \mathrm{msec}$ (depending on the group of participants) by a pattern mask (seven gray ampersands), thus resulting in a prime-mask stimulus onset asynchrony (SOA) of either $33 \mathrm{msec}^{1}$ or $167 \mathrm{msec}$, respectively. The masked prime word was always followed by a central target, which consisted of seven ampersands displayed - until response-in either red or green, with participants being required to make a button- 
press response to indicate the target color as quickly as possible. For both groups of participants, the prime-target SOA remained fixed at $300 \mathrm{msec}$. Prime and target stimuli were incongruent (e.g., RED-green target) on $75 \%$ of the trials and congruent (e.g., RED-red target) on the remaining 25\%. Merikle and Joordens (1997b) found a significant crossover interaction between masking condition and prime-target congruency: With a delayed mask (i.e., a prime-mask SOA of $167 \mathrm{msec}$ ), RTs were shorter on incongruent than on congruent trials. Such a reversed (i.e., facilitatory) Stroop effect suggests that the participants consciously identified the prime word followed by a delayed mask and then used the predictive information provided by the word to anticipate the target color (see also Logan, Zbrodoff, \& Williamson, 1984). On the contrary, with an immediate mask (i.e., a primemask SOA of $33 \mathrm{msec}$ ), a typical Stroop interference effect emerged. This crossover in performance (i.e., reversed Stroop vs. interference effect) provides an additional qualitative difference that distinguishes conscious from unconscious perception.

In a series of recent experiments using Merikle and Joordens's (1997b) procedure (e.g., Daza \& Ortells, 2000; Daza, Ortells, \& Fox, 2002), we have replicated and extended the findings of these authors. Daza et al. have shown that the behavioral consequences of perceiving a stimulus with and without phenomenological awareness are qualitatively different not only by the sign of the corresponding Stroop priming effect (i.e., interference vs. facilitation), but also by the time course of each priming effect. To illustrate, when the prime word was immediately masked so that participants reported a complete absence of conscious awareness of a word's identity, a reliable Stroop interference was consistently found at a prime-target SOA of $300 \mathrm{msec}$, which was similar in size to that reported by Merikle and Joordens (1997b). In addition, whereas such an interference effect was still significant at a prime-target SOA of $400 \mathrm{msec}$, it declined to zero at SOA intervals of $500 \mathrm{msec}$ and $700 \mathrm{msec}$ (Daza et al., 2002, Experiments 2 and 3), suggesting a relatively fast decay over time for the supposedly automatic Stroop priming effect. Regarding the prime words that were followed by a delayed mask, an opposite facilitation (i.e., reversed Stroop) effect was obtained, although this effect reached significance at prime-target SOAs of $400 \mathrm{msec}$ or longer. At an SOA of $300 \mathrm{msec}$, we consistently failed to replicate the reversed Stroop effect reported by Merikle and Joordens (1997b), regardless of whether our participants were either more or less actively encouraged to rely on the predictive information provided by the word to optimize their performance. The fact that in all of our experiments the participants' selfreports indicated that they were aware of the word's identity on most (or many) of the delayed mask trials suggests that consciously perceiving a stimulus constitutes a necessary but not a sufficient condition for that stimulus to guide intentional actions. To the extent that a reversed Stroop effect reflects mainly the contribution of strategic processes, and on the basis of the literature suggesting that controlled (strategic) processes build up much more slowly (and are often more sustained) than automatic processes (e.g., de Groot, 1984; Neely, 1977; Ortells, Abad, Noguera, \& Lupiáñez, 2001; Posner \& Snyder, 1975; Shenaut \& Ober, 1996; Shiffrin \& Schneider, 1977), Daza et al.'s findings suggest that a primetarget SOA of $300 \mathrm{msec}$ would not give most observers sufficient time to use the prime word strategically to anticipate the target color. ${ }^{2}$

It should be noted, however, that the disappearance of the automatic Stroop interference with the immediate mask in Daza et al.'s (2002) study, at SOAs of $500 \mathrm{msec}$ or longer, could be viewed as a somewhat surprising finding (although see Di Pace, Longoni, \& Zoccolotti, 1991; Greenwald et al., 1996). To the extent that several prior studies have shown relatively long-lasting priming effects from unconsciously perceived stimuli (e.g., Balota, 1983; Fowler, Wolford, Slade, \& Tassinary, 1981; Marcel, 1980, 1983a, 1983b), we considered it important to replicate the differential SOA functions from immediately versus delayed masked words reported by Daza et al.

It is important to note that since both Merikle and Joordens (1997b) and Daza et al. (2002) used a color-naming task, it is unclear whether the qualitatively different priming effects from consciously and unconsciously perceived words were indeed achieved at a level of semantic representation. This is an important question, since the depth of processing achieved by an unconsciously perceived stimulus has constituted a long-standing issue in contemporary psychology (Damian, 2001). Accordingly, in the present study we examined the consistency and generality of the differential time course of priming effects reported by Daza et al. under immediate versus delayed mask conditions, but using a semantic judgment task instead of a Stroop task.

\section{EXPERIMENT 1}

The basic procedure used in this and in the following experiment was as follows: On each trial, an uppercase prime word was centrally displayed for $33 \mathrm{msec}$ and followed either immediately or after a variable delay (depending on the experimental group) by a pattern mask. The mask offset was followed by a centrally displayed lowercase target word on which the participants performed a two-choice categorization (animal vs. body part) task (see Figure 1).

On $80 \%$ of the trials (unrelated condition), the prime and target words belonged to different semantic categories (e.g., COW-finger; HAND-bull), whereas on the remaining $20 \%$ of the trials (related condition) the primetarget pairs were always highly associated words of the same semantic category (e.g., COW-bull; HAND-finger). As in our Stroop studies, irrespective of whether the prime word was followed by an immediate mask or a delayed mask, the participants were encouraged to use the 
IMMEDIATE MASK

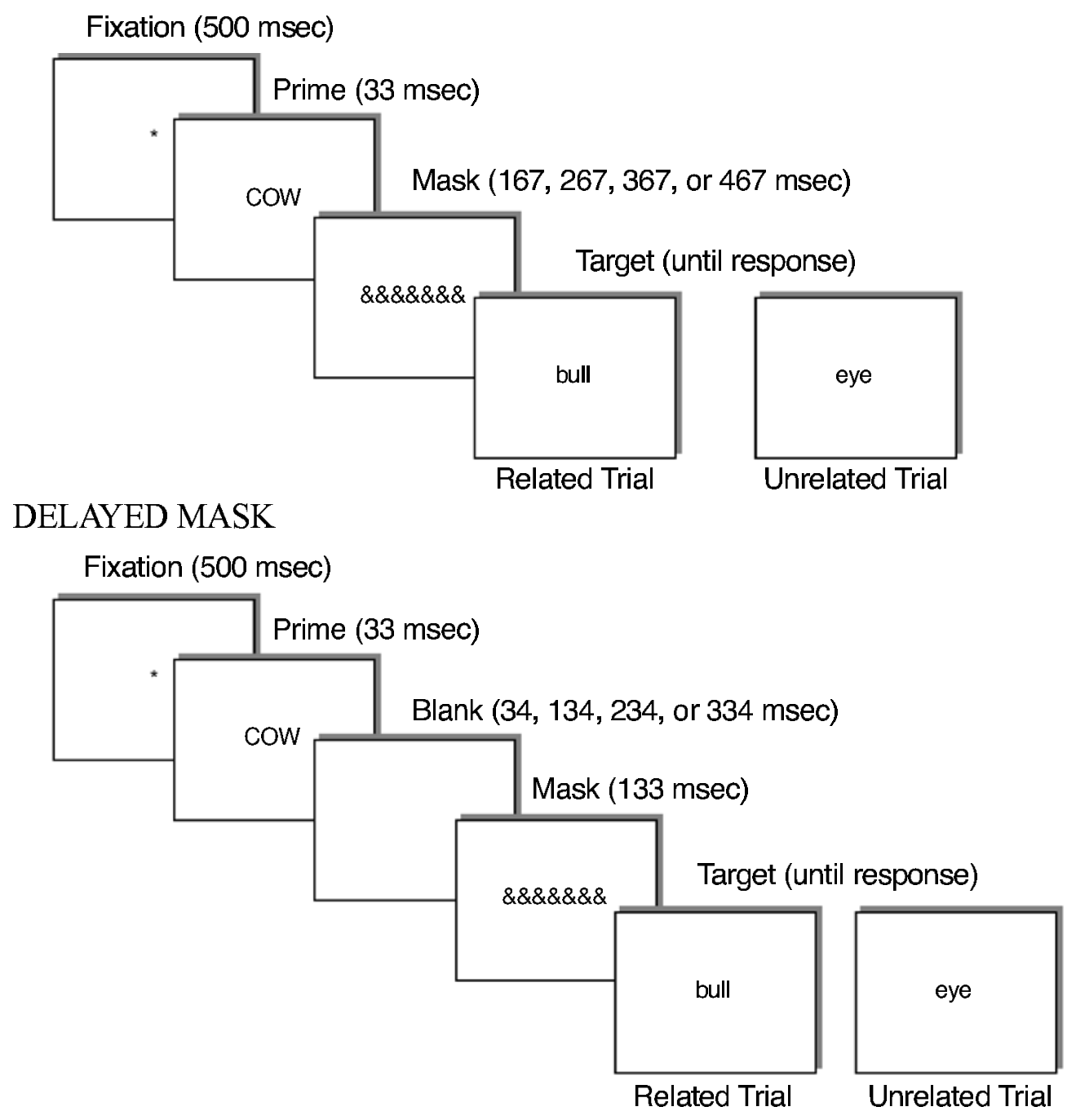

Figure 1. Sequence of events for trials in Experiment 1. The sample word stimuli shown here have been translated from Spanish to English.

predictive information provided by the prime word to optimize their categorization performance. So, given a particular prime word, they should expect that the upcoming target would belong to a different semantic category, since the unrelated trials were much more frequent than the related trials (see also Neely, 1977, for a similar procedure). To investigate the time course of priming effects of words presented under immediate versus delayed masking conditions, the prime-target SOA was manipulated between participants at four levels: 200, 300, 400, and $500 \mathrm{msec}$.

\section{Method}

Participants. One hundred twenty-eight undergraduate students at the University of Almería (32 for each of the four groups) participated in a single experimental session for course credit. All had normal or corrected-to-normal vision and were between the ages of 19 and 30 years $(M=24.5$ years).

Apparatus and Stimuli. The stimuli were displayed on a VGA color monitor controlled by Micro Experimental Laboratory (MEL) software (Schneider, 1988) implemented on an IBM-PC compatible computer. Responses were collected on a computer keyboard; response accuracy and latency to the nearest millisecond were measured by the MEL software. All the stimuli were displayed in gray characters (with each character subtending about $0.35^{\circ}$ horizontally and $0.52^{\circ}$ vertically) against a black background and were centered both horizontally and vertically at a viewing distance of approximately $60 \mathrm{~cm}$. Eight concrete and familiar words in the Spanish language were selected from the norms of Soto, Sebastián, García, and Del Amo (1982): four were the names of animals (vaca, toro, rana, and sapo-_cow," "bull," "frog," and "toad," respectively) and four were the names of body parts (mano, dedo, cara, and ojos- "hand," "finger," "face," and "eyes," respectively). All of these words were used as both prime and target stimuli throughout the experiment, 
the only difference being that they were displayed in uppercase characters when they appeared as primes and in lowercase characters when they appeared as target stimuli. For each participant and each block of trials, each word appeared 15 times as a prime and 15 times as a target stimulus ( 3 times on related trials and 12 times on unrelated trials). A string of seven gray ampersands ( $\& \& \& \& \& \& \&)$ subtending about $2.46^{\circ}$ horizontally and $0.52^{\circ}$ vertically was used as the pattern mask. The participants indicated the category of the target (animal vs. body part) by pressing either the $\mathrm{M}$ or the $\mathrm{C}$ key on the computer keyboard. Mapping of responses and correct key were counterbalanced across participants.

Design and Procedure. The participants were tested individually in a sound-damped, dimly lit room. General task instructions were displayed on the monitor and were also relayed verbally. The timing of the specific stimulus events on each trial for the immediate masking condition was as follows: (1) A fixation display (*) was presented for $500 \mathrm{msec}$; (2) an uppercase prime word was presented for $33 \mathrm{msec}$; (3) the mask (i.e., $\& \& \& \& \& \& \&$ ) was presented for $167,267,367$, or $467 \mathrm{msec}$, depending on the group of participants (resulting in prime-target SOAs of 200, 300, 400, and $500 \mathrm{msec}$, respectively); and (4) a lowercase target word (presented until response) appeared, for which the participants made a categorization judgment (animal vs. body part). Within each block of trials, $80 \%$ were unrelated trials, on which the target belonged to a different semantic category than that of the prime. The remaining $20 \%$ were related trials, on which the target was always a highly associated word of the same semantic category as that of the prime (e.g., cow-bull; HAND-finger). The computer emitted a 500-msec beep if the participant made an error. Following the participant's response, a new trial began.

The sequence of events on each trial for the delayed masking condition was the same as that under the immediate masking condition, the only difference being that the presentation of the 33-msec prime word was now followed by a blank screen for 34, 134, 234, or $334 \mathrm{msec}$ (depending on the group) and then followed by the ampersand mask for $133 \mathrm{msec}$ and by the word target (resulting again in prime-target SOAs of 200, 300, 400, and $500 \mathrm{msec}$, respectively). Note that whereas the prime-mask SOA remained fixed at $33 \mathrm{msec}$ for the immediate mask condition, the corresponding SOA was of $67,167,267$, or $367 \mathrm{msec}$ (depending of the prime-target SOA group) for the delayed masking condition.

Each participant took part in a single session (lasting about $30 \mathrm{~min}$ ) consisting of two blocks of 146 trials (26 practice trials followed by 120 experimental trials), one block for each masking condition (i.e., immediate masking and delayed masking). The order of the blocks was counterbalanced across participants. Of the 120 experimental trials of each block, $96(80 \%)$ were unrelated and 24 (20\%) were related (the participants were informed of that differential proportion of unrelated and related trials). Within each of these two trial sets, the target word belonged to either the animals or the body parts category on the same number of trials. The participants initiated each trial block by pressing the space bar on the computer keyboard. Once a block of trials was initiated, it ran to completion, so the participants could rest only between blocks. After completing each trial block, the participants were asked whether they had generally been able to identify the prime words preceding the masking pattern.

\section{Results and Discussion}

Mean RTs and error percentages were entered in two $2 \times 2 \times 4$ analyses of variance (ANOVAs) with masking condition (immediate vs. delayed) and prime-target relationship (unrelated vs. related) as within-participants factors and prime-target SOA (200 vs. 300 vs. 400 vs. $500 \mathrm{msec}$ ) as a between-participants factor.
In the analysis of RTs, there was a significant main effect of masking condition $\left[F(1,124)=48.3, M S_{\mathrm{e}}=\right.$ $17,634, p<.001]$, such that RTs were reliably shorter with an immediate $(658-\mathrm{msec})$ than with a delayed (740-msec) mask. Of more interest was the fact that a significant crossover interaction between masking condition and prime-target relationship was also found $\left[F(1,124)=23.1, M S_{\mathrm{e}}=2,403, p<.001\right]$. As in the Stroop study reported by Merikle and Joordens (1997b; see also Daza et al., 2002), such an interaction shows that perception with awareness and perception without awareness can lead to qualitatively different behavioral consequences. In the current task, an immediate mask produced a positive semantic priming effect (i.e., shorter RTs on related relative to unrelated trials) of $+22 \mathrm{msec}$ $\left[F(1,124)=28, M S_{\mathrm{e}}=1,114, p<.001\right]$. This suggests that a prime word presented for $33 \mathrm{msec}$ and immediately masked may be processed at a semantic level of representation, in spite of participants' reports of a complete absence of conscious awareness of the word's identity.

In contrast, with a delayed mask a reversed (i.e., negative) priming effect of $-20 \mathrm{msec}$ was found $[F(1,124)=$ 7.6, $M S_{\mathrm{e}}=3,262, p<.007$ ], such that RTs on the (less frequent) related trials were reliably longer than RTs on the unrelated trials. Such reversed priming indicates that the participants were aware of the prime words followed by a delayed mask and learned to use them strategically to anticipate the semantic category of the target word (i.e., the category opposite that of the prime).

These qualitatively different priming effects observed under each masking condition also showed a fairly different time course (see Table 1). This was revealed by a significant prime-target SOA $\times$ prime-target relationship interaction for both the immediate $[F(3,124)=3.57$, $\left.M S_{\mathrm{e}}=1,114, p<.02\right]$ and the delayed $[F(3,124)=3.14$, $\left.M S_{\mathrm{e}}=3,262, p<.03\right]$ mask conditions. The analyses of these interactions showed that the positive semantic priming observed with an immediate mask reached significance at the SOAs of $200 \mathrm{msec}[F(1,31)=31.2$, $\left.M S_{\mathrm{e}}=934, p<.001\right], 300 \mathrm{msec}\left[F(1,31)=7.4, M S_{\mathrm{e}}=\right.$ $1,364, p<.01]$, and $400 \mathrm{msec}\left[F(1,31)=6.3, M S_{\mathrm{e}}=\right.$ $509.5, p<.02]$. However, this supposedly automatic priming effect disappeared completely at the longest SOA of $500 \mathrm{msec}$. In contrast, the negative (strategic) priming obtained with the delayed mask was significant only at the SOAs of $400\left[F(1,31)=12.4, M S_{\mathrm{e}}=2,381, p<.001\right]$ and $500\left[F(1,31)=9.8, M S_{\mathrm{e}}=2,616, p<.004\right] \mathrm{msec}$, but not at the shortest SOAs of 200 and $300 \mathrm{msec}$ (see Table 1).

The present pattern of results replicates and extends that reported by Daza et al. (2002) with a Stroop task and is consistent with prior evidence from priming studies showing that controlled (strategic) processes build up much more slowly (and are often more sustained) than automatic processes (e.g., de Groot, 1984; Neely, 1977; Ortells et al., 2001; Posner \& Snyder, 1975; Shenaut \& Ober, 1996; Shiffrin \& Schneider, 1977).

The analysis of percentages of error mirrored the RT data. There was a significant main effect for masking 
Table 1

Mean Reaction Times (RTs, in Milliseconds), Percentages of Error (\% Error), and Differences in RTs [in Milliseconds; Facilitatory (+) or Reversed (-) Priming] as a Function of Prime-Target Stimulus Onset Asynchrony (SOA; 200 vs. 300 vs. 400 vs. 500 msec), Prime-Target Relationship (Unrelated vs. Related), and Masking Condition (Immediate vs. Delayed) for Experiment 1

\begin{tabular}{|c|c|c|c|c|c|}
\hline \multirow[b]{2}{*}{ Prime-Target SOA } & \multirow[b]{2}{*}{ Prime-Target Relationship } & \multicolumn{2}{|c|}{ Immediate } & \multicolumn{2}{|c|}{ Delayed } \\
\hline & & RT & $\%$ Error & RT & $\%$ Error \\
\hline \multirow[t]{3}{*}{$200 \mathrm{msec}$} & Unrelated & 699 & .06 & 751 & .06 \\
\hline & Related & 656 & .06 & 748 & .06 \\
\hline & Difference & +43 & & +3 & \\
\hline \multirow[t]{3}{*}{$300 \mathrm{msec}$} & Unrelated & 666 & .06 & 716 & .10 \\
\hline & Related & 641 & .07 & 715 & .11 \\
\hline & Difference & +25 & & +1 & \\
\hline \multirow[t]{3}{*}{$400 \mathrm{msec}$} & Unrelated & 636 & .08 & 726 & .10 \\
\hline & Related & 621 & .09 & 769 & .16 \\
\hline & Difference & +15 & & -43 & \\
\hline \multirow[t]{3}{*}{$500 \mathrm{msec}$} & Unrelated & 677 & .05 & 727 & .08 \\
\hline & Related & 671 & .05 & 767 & .14 \\
\hline & Difference & +6 & & -40 & \\
\hline
\end{tabular}

condition $\left[F(1,24)=32.6, M S_{\mathrm{e}}=0.0049, p<.001\right]$, such that there was a higher error rate with a delayed (.10) than with an immediate mask (.07), thus reflecting the RT results. The main effects of prime-target SOA $[F(3,124)=$ $\left.2.8, M S_{\mathrm{e}}=0.0204, p<.04\right]$ and prime-target relation$\operatorname{ship}\left[F(1,124)=16.9, M S_{\mathrm{e}}=0.0049, p<.001\right]$ were also significant, as were the following interactions: SOA $\times$ masking condition $\left[F(3,124)=3.8, M S_{\mathrm{e}}=0.00497, p<\right.$ $.001]$, SOA $\times$ prime-target relationship $[F(3,124)=2.85$, $\left.M S_{\mathrm{e}}=0.00303, p<.04\right]$, and masking condition $\times$ primetarget relationship $\left[F(1,124)=13.25, M S_{\mathrm{e}}=0.0022, p<\right.$ $.001]$. The three-way interaction between SOA, masking condition, and relationship was also marginally significant $\left[F(3,124)=2.5, M S_{\mathrm{e}}=0.0022, p<.06\right]$. The analyses of these interactions can be summarized as follows: Whereas with an immediate mask there was no significant facilitatory priming effect $(F<1)$, with a delayed mask a significant negative (strategic) priming effect was observed $\left[F(1,124)=22.9, M S_{\mathrm{e}}=0.0342, p<.001\right]$, such that the error rate was reliably higher on related (.12) than on unrelated (.08) trials. As can be observed from the RT data, such a strategic priming effect interacted with prime-target SOA $\left[F(3,124)=3.99, M S_{\mathrm{e}}=\right.$ $0.0034, p<.009]$. Thus, the negative priming effect reached significance only at the longer SOA conditions of $400 \mathrm{msec}\left[F(1,31)=9.9, M S_{\mathrm{e}}=0.0057, p<.004\right]$ and $500 \mathrm{msec}\left[F(1,31)=12.3, M S_{\mathrm{e}}=0.0036, p<.001\right]$, thus mirroring the RT pattern.

By using a dissociation procedure in which the participants engaged in semantic processing of masked words, the present experiment replicates and extends the main findings recently reported by Daza et al. (2002; see also Merikle \& Joordens, 1997b). First, we again found a crossover interaction between priming effects and masking condition, which revealed qualitatively different (i.e., positive vs. negative) priming effects stemming from words followed by an immediate versus a delayed mask.
Second, both types of priming effects also showed a fairly different time course. The positive semantic priming with the immediate mask was significant at SOAs of 200,300 , and $400 \mathrm{msec}$, but it completely disappeared at the longest SOA of $500 \mathrm{msec}$. Conversely, with the delayed mask a reliable reversed (i.e., negative) priming effect emerged at the SOA of $400 \mathrm{msec}$ or longer, but not at the shorter SOAs of 200 and $300 \mathrm{msec}$.

It could be argued that the lack of reversed priming effects under the delayed masking condition at the shorter SOAs of 200 and $300 \mathrm{msec}$ (see also Daza et al., 2002) does not necessarily reflect the absence of strategic influences at those time intervals. Rather, it could be that the strategic processes contribute immediately, but their influence is overridden by an equally large automatic influence. As the automatic influence subsides (i.e., as the SOA is lengthened), the strategic influences would then predominate. To examine whether the reversed priming effects in our task reflect mainly the contribution of strategic (controlled) processes or, rather, a combination of both strategic and automatic influences, we conducted a second experiment, in which the level of practice with the task was manipulated.

\section{EXPERIMENT 2}

The present experiment was procedurally similar to Experiment 1, with just three exceptions: (1) The presence of either an immediate or a delayed mask was manipulated between participants, (2) the prime-target SOA remained fixed at $400 \mathrm{msec},{ }^{3}$ and (3) the practice with the task was manipulated such that each participant carried out three consecutive blocks of trials. To the extent that obtaining a reversed (negative) priming effect under the delayed mask condition requires that participants learn to use the prime word strategically to anticipate the target category (see note 2 ), we expected that 
such a strategic effect might be reliably influenced by practice. More specifically, a controlled mechanism should build up throughout the experiment, since the participants would recognize the utility of a strategy (see ThompsonSchill, Kurtz, \& Gabrieli, 1998, for a similar argument). In contrast, if the positive priming with an immediate mask reflects automatic semantic processing, such an effect should already be present at the beginning of the experiment, with priming effects being comparable between trial blocks. In other words, we expected that priming effects should interact with task practice with a delayed mask but not with an immediate mask.

\section{Method}

Participants. Forty-eight undergraduate students at the University of Almería (24 in each experimental group) participated in the experiments. All had normal or corrected-to-norma 1 vision and were between the ages of 19 and 29 years $(M=24$ years).

Stimuli and Procedure. These were similar to those of Experiment 1 , except that in the current study (1) the presence of either an immediate or a delayed mask was manipulated between participants and (2) the participants in each group carried out three consecutive blocks of 80 trials per block (64 unrelated and 16 related trials).

\section{Results and Discussion}

Mean RTs and error percentages were entered in two $3 \times 2 \times 2$ ANOVAs, with task practice (Trial Block 1 vs. 2 vs. 3 ) and prime-target relationship (unrelated vs. related) as within-participants factors and masking condition (immediate vs. delayed) as a between-participants factor. The mean RTs and percentages of errors for each condition are presented in Table 2.

In the analysis of RTs, there was a significant main effect of task practice $\left[F(2,92)=20.2, M S_{\mathrm{e}}=10,510, p<\right.$ $.001]$, which revealed increasingly shorter RTs throughout blocks of trials (Block 1, 797 msec; Block 2, 728 msec; Block 3, $707 \mathrm{msec})$. Whereas the overall RTs were again shorter with the immediate mask $(714 \mathrm{msec})$ than with the delayed mask (774 $\mathrm{msec})$, such a difference did not reach statistical significance $[F(1,46)=1.9, p>$ .17], as was the case in Experiment 1. There were also significant interactions between masking condition and prime-target relationship $\left[F(1,46)=14.4, M S_{\mathrm{e}}=3,517.5\right.$, $p<.001]$ and between masking condition and task practice $\left[F(2,92)=3.8, M S_{\mathrm{e}}=10,510, p<.03\right]$. No other interactions reached significance. The results of additional two-way ANOVAs on each masking condition can be summarized as follows: As in Experiment 1, the prime words immediately followed by the mask produced a significant positive priming of $+29 \mathrm{msec}[F(1,23)=13.6$, $\left.M S_{\mathrm{e}}=2,217, p<.001\right]$, suggesting an automatic processing of those words at the level of meaning. In addition, whereas RTs were increasingly shorter throughout the trial blocks in the immediate masking condition, the level of practice did not influence the magnitude of positive priming (see Table 2), as is revealed by the absence of a significant interaction between task practice and prime-target relationship $(F<1)$.

In contrast, the prime words followed by a delayed mask produced an opposite (negative) priming of $-24 \mathrm{msec}$ $\left[F(1,23)=4.4, M S_{\mathrm{e}}=4,818, p<.048\right]$, thus replicating the results of Experiment 1. Interestingly, such a priming effect was influenced by task practice, as is revealed by a marginally significant interaction between these two factors $\left[F(2,46)=2.97, M S_{\mathrm{e}}=3,679, p<.06\right]$. Thus, no significant priming effect was observed in Trial Block 1 $(+11 \mathrm{msec} ; F<1)$, with the strategic (reversed) priming emerging in Trial Block $2[-43 \mathrm{msec} ; F(1,23)=3.6$, $\left.M S_{\mathrm{e}}=6,370, p<.07\right]$ and remaining in Trial Block 3 $\left[-40 \mathrm{msec} ; F(1,23)=11.8, M S_{\mathrm{e}}=1,595, p<.002\right] .4$

The analysis of percentages of error showed a significant main effect for prime-target relationship $[F(1,46)=$ $\left.13.8, M S_{\mathrm{e}}=0.0069, p<.001\right]$, as did the interaction of this factor with masking condition $[F(1,46)=11.5$, $\left.M S_{\mathrm{e}}=0.0069, p<.001\right]$. The analysis of this interaction revealed a significant reversed priming effect under the delayed masking condition $\left[F(1,23)=15.9, M S_{\mathrm{e}}=\right.$ $0.0109, p<.001]$, a result which mirrors that obtained in the RT data.

\section{GENERAL DISCUSSION}

Over the last two decades, an increasing number of researchers have attempted not only to prove the existence of unconscious perceptual processes but also to demon-

Table 2

Mean Reaction Times (RTs, in Milliseconds), Percentages of Error (\% Error), and Differences in RTs [in Milliseconds; Facilitatory (+) or Reversed (-) Priming] as a Function of Masking Condition (Immediate vs. Delayed), Prime-Target Relationship (Unrelated vs. Related), and Task Practice (Trial Blocks 1, 2, and 3) for Experiment 2

\begin{tabular}{|c|c|c|c|c|c|c|c|}
\hline \multirow[b]{3}{*}{ Masking Condition } & \multirow[b]{3}{*}{ Prime-Target Relationship } & \multicolumn{6}{|c|}{ Trial Block } \\
\hline & & \multicolumn{2}{|c|}{ Block 1} & \multicolumn{2}{|c|}{ Block 2} & \multicolumn{2}{|c|}{ Block 3} \\
\hline & & RT & $\%$ Error & RT & $\%$ Error & RT & $\%$ Error \\
\hline \multirow[t]{3}{*}{ Immediate } & Unrelated & 801 & .09 & 714 & .07 & 669 & .06 \\
\hline & Related & 770 & .09 & 687 & .07 & 641 & .06 \\
\hline & Difference & +31 & & +27 & & +28 & \\
\hline \multirow[t]{3}{*}{ Delayed } & Unrelated & 814 & .07 & 734 & .06 & 739 & .06 \\
\hline & Related & 803 & .12 & 777 & .15 & 779 & .13 \\
\hline & Difference & +11 & & -43 & & -40 & \\
\hline
\end{tabular}


strate that stimuli of which participants are not aware can produce qualitatively different behavioral effects in comparison with when they are aware of those stimuli (e.g., Correa et al., 2002; Debner \& Jacoby, 1994; Groeger, 1984, 1988; Marcel, 1980; Merikle \& Joordens, 1997b; Murphy \& Zajonc, 1993). This is the case, for example, of a series of recent Stroop priming studies that have consistently shown that individuals can use predictive strategies based on stimulus redundancy (i.e., predicting the color of forthcoming targets) only when the predictive stimuli are consciously perceived (e.g., Daza et al., 2002; Merikle \& Joordens, 1997b; Merikle et al., 1995). In the present research, we sought to extend these findings by using a task demanding semantic processing of stimuli. The participants in our experiments were required to identify the semantic category (animals vs. body parts) of a central lowercase target word, which was preceded, for a variable time interval (depending on the experiment), by either an unrelated word (on $80 \%$ of the trials) or a categorically related central prime word in uppercase (on $20 \%$ of the trials). As in the Stroop priming studies by both Merikle and Joordens (1997b) and Daza et al. (2002), the likelihood that the prime words would be perceived with or without awareness was controlled by varying stimulus quality, such that the prime word was always followed by a mask appearing either immediately (i.e., a prime-mask SOA of $33 \mathrm{msec}$ ) or after a variable delay (depending on the experiment) following the word offset.

There are three main findings of the present research. First, we found that presenting a word under immediate versus delayed masking conditions gave rise to qualitatively different behavioral effects (i.e., positive vs. negative semantic priming effects, respectively), a result that replicates and extends prior findings (e.g., Daza et al., 2002; Merikle \& Joordens, 1997b; Merikle et al., 1995). Of more importance, the demonstration of a crossover interaction between priming effects and masking condition with a task demanding a semantic level of representation (i.e., an animals vs. body parts judgment) is consistent with behavioral and neuroscientific evidence (see, e.g., Kiefer, 2002; Merikle \& Daneman, 1998), suggesting that semantic activation can occur without conscious identification of word stimuli, at least when they are presented below what Cheesman and Merikle (1986) referred to as a subjective threshold.

Given the small number of stimuli used in our research (i.e., two semantic categories, each of them having only four items), one could argue that after some practice priming effects similar to those reported here could emerge with other sorts of stimuli, such as letters or digits that are randomly grouped together. In other words, it could be the case that the positive priming effects with the immediate mask were due to repeated exposures of the same prime-target pairs, thus suggesting an associative basis (i.e., one at a lower perceptual level) rather than a semantic basis for that supposedly automatic priming. But several observations are pertinent here. First, our related trials always consisted of categorically related word pairs that were both strongly associated (in forward and backward directions) and semantically similar (i.e., with high semantic overlap). ${ }^{5}$ There is evidence that priming effects in the absence of semantic relatedness are usually the result of controlled mechanisms. In contrast, semantic relatedness seems to be necessary and sufficient to produce automatic priming effects (see, e.g., Seidenberg, Waters, Sanders, \& Langer, 1984; Thompson-Schill et al., 1998). For example, Thompson-Schill et al. used asymmetrically associated word pairs in a priming procedure which included the use of a short prime-target SOA of $250 \mathrm{msec}$ and a small proportion of related trials aimed at minimizing potential influences of controlled (strategic) processes. They found reliable positive priming for semantically related prime-target pairs regardless of the degree (i.e., forward vs. backward) of associative relatedness. Yet, for semantically unrelated words, no automatic priming was found, even if there was an associative (i.e., forward) prime-target relationship (see also McRae \& Boisvert, 1996). On the other hand, given the relative frequencies of related $(20 \%)$ and unrelated $(80 \%)$ trials in our research, there was no particular prime-target pair that occurred with more probability than others throughout the experiment. To illustrate, if HAND was the prime word, the upcoming word target could be finger (on related trials), ${ }^{6}$ or cow, bull, frog, or toad (on unrelated trials), with these five words being equiprobable. Accordingly, even if the participants were able to consciously identify the prime words immediately followed by a mask, they could only learn that the category of the upcoming target would more likely be the opposite of that of the prime (e.g., HAND followed by an animal word). Yet they would be unable to predict the word target's identity. Finally, if the positive priming effects with the immediate mask depended on learned strategies due to stimulus repetition, it is unclear why those effects emerged at SOAs shorter than those of the negative priming effects with the delayed mask. Likewise, there should be an increase in the effectiveness of the strategy with practice, which should cause an increase in priming over blocks. But this was not the case in Experiment 2 (see below). Despite the absence of practice trials in that experiment, the primes immediately followed by a mask produced reliable positive priming at the beginning of the experiment, and the magnitude of this effect was similar across trial blocks.

The second main finding of the present research was that priming effects under immediate versus delayed masking conditions showed a fairly different time course, thus replicating the findings previously reported by Daza et al. (2002) with a Stroop task. When the prime word was immediately masked such that the participants consistently reported that they were unaware of the word's identity, a reliable facilitatory (i.e., positive) priming effect was found in both Experiments 1 and 2 . This supposedly automatic priming effect was significant at the shortest prime-target SOA interval (i.e., 
$200 \mathrm{msec}$ in Experiment 1), but it decayed rapidly over time, and the effect disappeared completely at an SOA of $500 \mathrm{msec}$ (Experiment 1). The reasons for the discrepancies between these results and those reported by some prior studies showing a longer persistence of automatic priming effects remain unclear. In any case, the fact that the present results mirrored those reported by Daza et al. using a different task suggests that the prime-target SOA can critically determine the emergence of automatic priming effects from unconsciously perceived stimuli in this kind of dissociation procedure (see also Greenwald et al., 1996). On the other hand, the prime words followed by a delayed mask produced an opposite negative priming effect. As in the Stroop priming study by Merikle and Joordens (1997b; see also Daza et al., 2002), such a finding demonstrates that participants consciously identified those words and successfully used the predictive information provided by the prime word to anticipate the target category. Interestingly, as is shown in Experiment 1 (see Table 1), the negative priming effect was significant at a prime-target SOA of $400 \mathrm{msec}$ or longer, but not at the shorter SOA intervals of 200 and $300 \mathrm{msec}$. Such a time course of strategic priming effects exactly replicates that reported by Daza et al. (2002, Experiments 1 and 2) and is consistent with prior research showing that controlled processes build up much more slowly (and are often more sustained) than automatic processes (see, e.g., Di Pace et al., 1991; Neely, 1977; Ortells et al., 2001; Posner \& Snyder, 1975; Shenaut \& Ober, 1996; Shiffrin \& Schneider, 1977).

The third relevant finding of the present research was that priming effects of immediate versus delayed conditions were influenced differently by the level of practice with the task. The results of Experiment 2 showed that the emergence of a reliable strategic (negative) priming effect with a delayed mask required some level of practice with the task, since such an effect became significant only in the second block of trials (but not at the first block). In contrast, as is shown in Table 2, the facilitatory priming effects observed with an immediate mask were significant from the first trial block, and they were of a similar magnitude across the three blocks (as is revealed by the absence of a significant priming $\times$ task practice interaction).

To the extent that a primary purpose of Experiment 2 was to examine the effect of practice, the number of trials used in that experiment would seem to be relatively small. There is ample evidence that practice is an important determinant in the development of automaticity (e.g., in a controlled process's becoming automatic) and skilled performance. Within that research framework, the effects of practice have typically been investigated in studies using a large number of training sessions (e.g., Fisk \& Schneider, 1983; LaBerge, 1973; Logan, 1985; Shiffrin \& Schneider, 1977). But the point to be stressed here is that our practice manipulation was not aimed at examining the development of automaticity. On the contrary, the goal of Experiment 2 was to investigate to what extent a strategy-dependent process, such as using the predictive information provided by a prime word, would require some amount of practice for adequate implementation (see also Thompson-Schill et al., 1998, for a similar line of argument). This was the reason for which there were no practice trials in Experiment 2. As has been stated elsewhere (see note 2), by using a Stroop priming procedure similar to that of the present research (i.e., with incongruent prime-target pairings being more frequent that congruent pairings), Merikle and Joordens (1997b) had to give considerable training to some of their participants in order for them to be able to use the prime word strategically to anticipate the target color. Note also that an adequate implementation of this kind of predictive strategy would also require participants to be able to identify the stimulus consciously (see also Debner \& Jacoby, 1994; Merikle \& Joordens, 1997a). Thus, we expected the practice manipulation to be important with a delayed but not with an immediate mask, as was actually the case in Experiment 2.

Taken together, the present findings strengthen those obtained in previous studies (e.g., Daza et al., 2002; Merikle \& Joordens, 1997b), which suggests that the qualitatively different priming effects stemming from conscious and unconscious perception in this kind of dissociative procedure do indeed reflect the contribution of strategic (controlled) and automatic processes, respectively.

\section{REFERENCES}

Abad, M. J. F., Noguera, C., \& Ortells, J. J. (2003). Influence of prime-target relationship on semantic priming effects from words in a lexical-decision task. Acta Psychologica, 113, 283-295.

Balota, D. A. (1983). Automatic semantic activation and episodic memory. Journal of Verbal Learning \& Verbal Behavior, 22, 88-104.

Cheesman, J., \& Merikle, P. M. (1985). Word recognition and consciousness. In D. Besner, T. G. Waller, \& G. E. MacKinnon (Eds.), Reading research: Advances in theory and practice (Vol. 5, pp. 311352). New York: Academic Press.

Cheesman, J., \& Merikle, P. M. (1986). Distinguishing conscious from unconscious perceptual processes. Canadian Journal of Psychology, 40, 343-367.

Correa, A., Fox, E., Carmona, E., Noguera, C., Lupiáñez, J., \& Tudela, P. (2002, April). The processing of emotional faces at two levels of awareness in subclinical anxiety. Poster presented at the IV Conference of the Spanish Society for Experimental Psychology, Oviedo.

Damian, M. F. (2001). Congruity effects evoked by subliminally presented primes: Automaticity rather than semantic processing. Journal of Experimental Psychology: Human Perception \& Performance, 27, 154-165.

Daza, M. T., \& Ortells, J. J. (2000, March). Procesamiento automático vs. controlado de palabras: Relación entre atención y conciencia [Automatic vs. controlled word processing: Relationship between attention and consciousness]. Paper presented at the III Conference of the Spanish Society for Experimental Psychology, Barcelona.

Daza, M. T., Ortells, J. J., \& Fox, E. (2002). Perception without awareness: Further evidence from a Stroop priming task. Perception \& Psychophysics, 64, 1316-1324.

Debner, J. A., \& JAcoby, L. L. (1994). Unconscious perception: Attention, awareness, and control. Journal of Experimental Psychology: Learning, Memory, \& Cognition, 20, 304-317. 
DE Groot, A. M. B. (1984). Primed lexical decision: Combined effects of the proportion of related prime-target pairs and the stimulus-onset asynchrony of prime and target. Quarterly Journal of Experimental Psychology, 36A, 253-280.

Di Pace, E., Longoni, A. M., \& Zoccolotti, P. (1991). Semantic processing of unattended parafoveal words. Acta Psychologica, 77, 21 34.

Draine, S. C., \& Greenwald, A. G. (1998). Replicable unconscious semantic priming. Journal of Experimental Psychology: General, 127, 286-303.

ERIKSEN, C. W. (1960). Discrimination and learning without awareness: A methodological survey and evaluation. Psychology Review, 67, 279-300.

Fisk, A. D., \& SchneIder, W. (1983). Category and word search: Generalizing search principles to complex processing. Journal of Experimental Psychology: Learning, Memory, \& Cognition, 9, 177-195.

Fowler, C. A., Wolford, G., Slade, R. \& Tassinary, L. (1981). Lexical access with and without awareness. Journal of Experimental Psychology: General, 110, 341-362.

Greenwald, A. G., Draine, S. C., \& Abrams, R. L. (1996). Three cognitive markers of unconscious semantic activation. Science, $\mathbf{2 7 3}$, 1699-1702.

Groeger, J. A. (1984). Evidence of unconscious semantic processing from a forced-error situation. British Journal of Psychology, 75, 305314.

Groeger, J. A. (1988). Qualitatively different effects of undetected and unidentified auditory primes. Quarterly Journal of Experimental Psychology, 40A, 323-339.

Holender, D. (1986). Semantic activation without conscious identification in dichotic listening, parafoveal vision, and visual masking: A survey and appraisal. Behavioral \& Brain Sciences, 9, 1-66.

JACOBY, L. L., LindSAY, D. S., \& ToTH, J. P. (1992). Unconscious influences revealed: Attention, awareness, and control. American Psychologist, 47, 802-809.

KIEFER, M. (2002). The N400 is modulated by unconsciously perceived masked words: Further evidence for an automatic spreading activation account of N400 priming effects. Cognitive Brain Research, 13, 27-39.

LaBerge, D. (1973). Attention and the measurement of perceptual learning. Memory \& Cognition, 1, 268-276.

LogAN, G. D. (1985). Skill and automaticity: Relations, implications, and future directions. Canadian Journal of Psychology, 39, 367-386.

Logan, G. D., \& Zвrodoff, N. J. (1982). Constraints on strategy construction in a speeded discrimination task. Journal of Experimental Psychology: Human Perception \& Performance, 8, 502-520.

Logan, G. D., Zbrodoff, N. J., \& Williamson, J. (1984). Strategies in the color-word Stroop task. Bulletin of the Psychonomic Society, 22, 135-138.

MARCEL, A. J. (1980). Conscious and preconscious recognition of polysemous words: Locating the selective effect of prior verbal context. In R. S. Nickerson (Ed.), Attention and performance VIII (pp. 435457). Hillsdale, NJ: Erlbaum.

Marcel, A. J. (1983a). Conscious and unconscious perception: An approach to the relation between phenomenal experience and perceptual processes. Cognitive Psychology, 15, 238-300.

MARCEL, A. J. (1983b). Conscious and unconscious perception: Experiments on visual masking and word recognition. Cognitive Psychology, 15, 197-237.

McRAe, K., \& Boisvert, S. (1996). The importance of automatic semantic relatedness priming for distributed models of word meaning. In Proceedings of the Eighteenth Annual Conference of the Cognitive Science Society (Vol. 18, pp. 278-283). Mahwah, NJ: Erlbaum.

Merikle, P. M., \& Daneman, M. (1998). Psychological investigations of unconscious perception. Journal of Consciousness Studies, 5, 5-18.

MerikLe, P. M., \& Joordens, S. (1997a). Measuring unconscious influences. In J. D. Cohen \& J. W. Schooler (Eds.), Scientific approaches to consciousness (pp. 109-123). Mahwah, NJ: Erlbaum.

Merikle, P. M., \& Joordens, S. (1997b). Parallels between perception without attention and perception without awareness. Consciousness \& Cognition, 6, 219-236.

Merikle, P. M., Joordens, S., \& Stolz, J. A. (1995). Measuring the relative magnitude of unconscious influences. Consciousness \& Cognition, 4, 422-439.

Merikle, P. M., \& ReIngold, E. M. (1998). On demonstrating unconscious perception: Comment on Draine and Greenwald (1998). Journal of Experimental Psychology: General, 127, 304-310.

Merikle, P. M., Smilek, D., \& Eastwood, J. D. (2001). Perception without awareness: Perspectives from cognitive psychology. Cognition, 79, 115-134.

MurPhy, S. T., \& ZaJonc, R. B. (1993). Affect, cognition, and awareness: Affective priming with optimal and suboptimal stimulus exposures. Journal of Personality \& Social Psychology, 64, 723-739.

NeELy, J. H. (1977). Semantic priming and retrieval from lexical memory: Roles of inhibitionless spreading activation and limited-capacity attention. Journal of Experimental Psychology: General, 106, 226-254.

Ortells, J. J., Abad, M. J. F., Noguera, C., \& Lupiáñez, J. (2001). Influence of prime-probe stimulus onset asynchrony and prime precuing manipulations on semantic priming effects with words in a lexical decision task. Journal of Experimental Psychology: Human Perception \& Performance, 27, 75-91.

Posner, M. I., \& SNyder, C. R. R. (1975). Attention and cognitive control. In R. L. Solso (Ed.), Information processing and cognition: The Loyola Symposium (pp. 55-58). Hillsdale, NJ: Erlbaum.

REINGOLD, E. M. (in press). Unconscious perception and the classic dissociation paradigm: A new angle? Perception \& Psychophysics.

Reingold, E. M., \& Merikle, P. M. (1988). Using direct and indirect measures to study perception without awareness. Perception \& Psychophysics, 44, 563-575.

Reingold, E. M., \& MerikLe, P. M. (1990). On the inter-relatedness of theory and measurement in the study of unconscious processes. Mind \& Language, 5, 9-28.

SCHNEIDER, W. (1988). Micro Experimental Laboratory: An integrated system for IBM-PC compatibles. Behavior Research Methods, Instruments, \& Computers, 20, 206-217.

Seidenberg, M. S., Waters, G. S., Sanders, M., \& Langer,P. (1984). Pre- and postlexical loci of contextual effects on word recognition. Memory \& Cognition, 12, 315-328.

Shenaut, G. K., \& Ober, B. A. (1996). Methodological control for semantic priming in Alzheimer's disease. Psychology \& Aging, 11, 443-448.

Shiffrin, R. M., \& Schneider, W. (1977). Controlled and automatic human information processing: II. Perceptual learning, automatic attending and a general theory. Psychological Review, 84, 127-190.

Soto, P., Sebastián, M. V., García, E., \& Del Amo, T. (1982). Categorización y datos normativos en España [Categorization and associative norms in Spain]. Madrid: Cantoblanco.

Stroop, J. R. (1935). Studies of interference in serial verbal reactions. Journal of Experimental Psychology, 18, 643-662.

Thompson-Schill, S. L., Kurtz, K. J., \& Gabrieli, J. D. E. (1998). Effects of semantic and associative relatedness on automatic priming. Journal of Memory \& Language, 38, 440-458.

\section{NOTES}

1. In a number of previous studies, Merikle and colleagues (e.g., Cheesman \& Merikle, 1985, 1986; Merikle et al., 1995) consistently found that a prime-mask SOA of $33 \mathrm{msec}$ is below most participants' threshold of subjective awareness. This result has been confirmed in a series of recent experiments in our labs. Thus, when we required participants to perform forced-choice binary tasks (e.g., an animate/inanimate judgment) on words presented for $33 \mathrm{msec}$ and immediately masked, their performance was reliably better than chance (i.e., $d^{\prime}>0$ ). Yet, they reported a complete phenomenal lack of stimulus awareness, suggesting that words presented under immediate masking conditions were below a subjective threshold but not below an objective threshold of stimulus awareness.

2. Note that less than one half of the participants in each of Daza et al.'s (2002) experiments showed a reversed (facilitatory) Stroop effect from consciously perceived stimuli at the shortest prime-target SOA $(300 \mathrm{msec})$. Whereas the reasons for the discrepancies between Daza et al.'s findings and those reported by Merikle and Joordens (1997b) at the 300-msec SOA remain unclear, an inspection of Figure 1 in Merikle 
and Joordens's paper (1997b, p. 224) suggests that the overall RTs in their study were shorter (i.e., below $400 \mathrm{msec}$ ) than those reported by Daza et al. (i.e., above $400 \mathrm{msec}$ ). Whereas none of the participants in our experiments had any prior experience with this kind of task, we have heard from both Phil Merikle (personal communication, July 16, 2001) and Steve Joordens (personal communication, October 25, 2001) that some of their participants were given considerable training in using the prime word to anticipate the target color. Furthermore, some of their participants may have been in other perception-without-awareness experiments-that is, experiments that would have given them experience with briefly presented and masked items. On the basis of prior evidence showing that the time necessary to implement strategic processes can be shortened by practice (e.g., Logan \& Zbrodoff, 1982; see also Logan, 1985), it thus remains possible that in Merikle and Joordens's (1997b) study, a seemingly short SOA of $300 \mathrm{msec}$ could still represent enough time for strategy development for a large proportion of their participants.

3. In the present experiment, we used a prime-target SOA of $400 \mathrm{msec}$, since this was the only SOA condition in which both the facilitatory and the reversed priming effects (under immediate vs. delayed masking conditions, respectively) had reached statistical significance in Experiment 1 (see Table 1).

4. It should be noted that the nonsignificant priming of $+11 \mathrm{msec}$ in the first trial block was the result of between-participants variability in the delayed masking group. Thus, less than one half (10) of the 24 participants showed strategic (i.e., negative) priming, whereas the remaining participants showed an opposite positive priming, although the prime words were clearly visible. In contrast, such participant variability was greatly reduced as task practice increased. Thus, in the second and third trial blocks, 16 and 20 participants, respectively, showed strategic (negative) priming (with the remaining 8 and 4 participants in the respective blocks showing positive priming). It appears, then, that whereas some participants in the delayed masking group did not need practice in order to use the prime strategically to anticipate the target category, this was not really the case for most of the participants, who required some training with the task (see also Daza et al., 2002, note 6, for similar results with a Stroop priming task).

5. In a series of lexical decision experiments (Abad, Noguera, \& Ortells, 2003), positive and negative semantic priming effects (from attended and unattended prime words, respectively) have consistently been found only when the prime-target pairs were highly associated words belonging to the same semantic category. In contrast, no priming evidence was observed for categorically related prime-target pairs that were weak associates and did not share many semantic features (e.g., giraffe-mouse; face-heart).

6 . To the extent that the related trials always consisted of strong associates from the same semantic category, the target stimulus following the prime word HAND on a related trial could only be the word finger, never the word face or eye.

(Manuscript received November 5, 2002; revision accepted for publication April 28, 2003.) 